\title{
BMJ Open How have journalists been affected psychologically by their coverage of the COVID-19 pandemic? A descriptive study of two international news organisations
}

Jonas Osmann (D) , ${ }^{1,2}$ Meera Selva, ${ }^{3}$ Anthony Feinstein ${ }^{1,2}$

To cite: 0 smann J, Selva M, Feinstein A. How have journalists been affected psychologically by their coverage of the COVID-19 pandemic? A descriptive study of two international news organisations. BMJ Open 2021;11:e045675. doi:10.1136/ bmjopen-2020-045675

- Prepublication history and additional supplemental material for this paper are available online. To view these files, please visit the journal online (http://dx.doi.org/10.1136/ bmjopen-2020-045675).

Received 16 0ctober 2020 Accepted 08 June 2021
Check for updates

(c) Author(s) (or their employer(s)) 2021. Re-use permitted under CC BY-NC. No commercial re-use. See rights and permissions. Published by BMJ.

${ }^{1}$ Department of Psychiatry, Sunnybrook Health Sciences Centre, Toronto, Ontario, Canada ${ }^{2}$ Institute of Medical Science, University of Toronto, Toronto, Ontario, Canada

${ }^{3}$ Reuters Institute for the Study of Journalism, University of Oxford, Oxford, UK

Correspondence to Dr Jonas Osmann; j.osmann@mail.utoronto.ca

\section{ABSTRACT}

Objectives The COVID-19 pandemic has presented unprecedented healthcare challenges. Journalists covering the pandemic at close quarters are working in ways akin to first responders, but nothing to date is known of the psychological distress this is potentially causing them. This study aims to determine whether journalists reporting on the COVID-19 crisis have been affected emotionally, and if so to assess the severity of their distress. It also investigates potential demographic and work-related predictors and whether news organisations had provided counselling to their journalists.

Participants A total of 111 journalists working for two international news organisations were approached of which $73(66 \%)$ participated in the study.

Primary and secondary outcome measures Symptoms of anxiety (Generalised Anxiety Disorder Scale-7 (GAD7)), depression (Patient Health Questionnaire (PHQ-9)), posttraumatic stress disorder (PTSD; PTSD Checklist for DSM-5 (PCL-5)), overall psychological distress (12-item General Health Questionnaire (GHQ-12)), and treatment. Results The percentages of journalists exceeding threshold scores for clinically significant anxiety, depression, PTSD and psychological distress were: GAD7, 26\%; PHQ-9, 20.5\%; PCL-5, 9.6\%; GHQ-12, 82.2\%. Journalists assigned to cover the pandemic $(n=54(74 \%))$ were significantly more anxious $(p<0.05)$. Journalists who received counselling $(n=38(52 \%))$ following the onset of the pandemic reported significantly fewer symptoms of anxiety $(p<0.01)$, depression $(p<0.01)$ and overall psychological distress $(p<0.01)$.

Conclusions Journalists covering the COVID-19 pandemic are experiencing levels of anxiety and depression similar to those seen in first responders. Psychological therapy provided in a timely manner can significantly alleviate emotional distress.

\section{INTRODUCTION}

Since its first emergence in 2019 in Wuhan, China, COVID-19 has posed a significant threat to public health ${ }^{1}$ with almost 39 million cases reported globally and 1,101,083 confirmed global deaths as of 16 October,
Strengths and limitations of this study

First study to investigate the psychological effects on journalists reporting on COVID-19.

- Multivariate regression modelling.

- Clear outcome measures.

No diagnoses with structural interviews.

2020. ${ }^{2}$ The pandemic has caused widespread emotional distress, with studies indicating moderate to severe levels of anxiety- or stressrelated symptoms in the general population in response. ${ }^{3-5}$ Elevated rates for posttraumatic stress disorder (PTSD) in members of the Chinese workforce,${ }^{6}$ heightened fear of infection and COVID-19-related worries in online samples, ${ }^{7-9}$ and increased anxiety in Chinese college students ${ }^{10}$ have also been reported.

Findings from research on the psychological distress of first responders and healthcare workers who have to deal with the consequences of the pandemic, directly suggest they are particularly vulnerable to COVID-19related psychological distress. ${ }^{11-14}$ Journalists have increasingly been recognised as first responders to hazardous events ${ }^{15}$ and often have to work in close proximity to the threat they are reporting on. However, no data are available on the potential psychological distress that covering the COVID-19 epidemic might cause them. It was with this in mind that the current study was undertaken.

The aim of our descriptive study was twofold. First, we sought to determine whether journalists reporting on the COVID-19 crisis have been affected emotionally and if so, to assess the severity of their distress. We also looked for potential demographic and work-related predictors, given that our previous research 
with journalists has revealed the importance of these factors as determinants of their mental health. ${ }^{16}{ }^{17}$ Finally, we looked at whether news organisations had provided counselling to their journalists. We hypothesised that journalists assigned to COVID-19 coverage directly would endorse more symptoms of emotional distress, anxiety, depression and posttraumatic stress than those who did not and that elevated rates of psychopathology would be alleviated by therapy received since the outbreak of the pandemic.

\section{METHODS}

\section{Participants}

A group of 111 journalists, engaged in current affairs reportage, primarily based in Europe and North America and whose contact details were provided by two international news agencies were approached via email (see invitation letter in online supplemental material 1 available at http://dx.doi.org/10.1136/bmjopen-2020-045675) to participate in the study. Of these, $73(66 \%)$ completed the study, 2 (2\%) opted out, and 36 (32\%) did not respond. Data collection was performed with Qualtrics, ${ }^{18}$ a secure online data collection tool licensed by the host institution. All data were collected between 28 April and 20 July 2020. Journalists were provided with a password and a unique link to enter the site, which allowed them to complete the study across multiple sessions. After logging in for the first time, journalists were presented with a detailed introduction to the study and a consent form. Clicking the consent button at the bottom of the form signalled their agreement to participate and automatically redirected participants to the first of seven questionnaires. All data were anonymised before performing the statistical analysis.

\section{Patient and public involvement}

No patients were involved in this study.

\section{Demographic and COVID-19-related data}

1. The general demographic data collected included age, gender, marital status, years worked as a journalist and level of education.

2. COVID-19-related data included asking journalists if they had covered health beats prior to the outbreak, if their employment had become more stressful due to COVID-19, if they had been tested for COVID-19, if they had colleagues who had died from the virus, if they had reported on COVID-19 directly, and if they had been offered counselling by their news organisation since the outbreak.

\section{Psychiatric data}

Four psychometric scales were used to collect the behavioural data.

1. Overall levels of psychological distress were assessed with the 12-item General Health Questionnaire (GHQ-12). ${ }^{19}$ Each item is scored 0-0-1-1 for responses that range from a 'better/healthier than normal' to a 'much worse/more than usual' option. A score of $\geqq$ 2 is indicative of psychiatric 'caseness', a marker for overall emotional distress. Cronbach's $\alpha$ for the GHQ12 was 0.84 .

2. The Generalised Anxiety Disorder Scale-7 (GAD-7) ${ }^{20}$ quantifies symptoms of generalised anxiety disorder. Responses are scored on a 4-point Likert scale $(0=$ 'Not at all' to $3=$ 'Nearly every day') with a maximum total of 21. A score of $\geqq 10$ is indicative of clinically significant anxiety. Cronbach's $\alpha$ was 0.91 .

3. Symptoms of depression were assessed with the Patient Health Questionnaire (PHQ-9). ${ }^{21}$ A 4-point-Likert scale $(0=$ 'Not at all' to $3=$ 'Nearly every day') is used to score responses. A score of $\geqq 10$ out of 27 is generally considered to be suggestive of the presence of major depression. Cronbach's $\alpha$ for the PHQ-9 was 0.86 .

4. The PTSD Checklist for DSM-5 (PCL-5) ${ }^{22}{ }^{23}$ was used to quantify the presence and severity of PTSD symptoms. Responses on the 20-item measure are scored on a 5-point Likert scale ranging from $0=$ 'Not at all' to 4 $=$ 'Extremely'. A cut-off score of $\geqq 33$ indicates a provisional PTSD diagnosis. ${ }^{20}$ Cronbach's $\alpha$ for the PCL-5 was 0.95 .

Journalists were asked whether they had ever sought mental health therapy prior to the pandemic. Journalists were also asked to complete two simple analogue scales to assess perceived degrees of stress $(0=$ no stress; $10=$ severe stress) and support ( $0=$ no support; $10=$ full support). Lastly, alcohol consumption was assessed in terms of units per week. A unit of alcohol was defined as a regular-size bottle of beer, a glass of wine, or a shot of spirits. Fourteen units of alcohol per week for men and nine units for women were considered the upper limits of acceptable weekly intake. ${ }^{24}$

\section{Statistical analysis}

All statistical analyses were performed in $\mathrm{R}$ version 3.6.3. ${ }^{25}$ Shapiro-Wilk tests revealed that assumptions of normality were violated for years of experience as a journalist $(\mathrm{W}=0.95, \mathrm{p}<0.01)$ and perceived levels of support $(\mathrm{W}=0.95, \mathrm{p}<0.01)$. Examinations of relationships involving these variables were therefore undertaken with Spearman's rank correlation coefficient. Group effects on variables that did not violate assumptions of normality were performed with t-tests.

Shapiro-Wilk tests of normality were significant for all psychiatric measures (GHQ-12: $\mathrm{W}=0.94, \mathrm{p}<0.01$; GAD-7: $\mathrm{W}=0.91, \mathrm{p}<0.001$; PHQ-9: $\mathrm{W}=0.93$, $\mathrm{p}<0.001$; PCL-9: $\mathrm{W}=0.83$, $\mathrm{p}<0.001)$. As such, predictors of overall emotional distress, anxiety, depression, and PTSD were sought with generalised linear models of the Poisson family type utilising log link.

\section{RESULTS}

\section{Demographic data}

The demographic and COVID-19-related data appear in table 1. On average, journalists who reported on COVID-19 directly were significantly younger $(\mathrm{W}=708, \mathrm{p}<0.05)$. Age was found to significantly correlate with years of work 


\begin{tabular}{|c|c|c|c|c|}
\hline & $\mathbf{n}$ & $\%$ & Mean & SD \\
\hline Age & 73 & 100 & 41.29 & 9.76 \\
\hline \multicolumn{5}{|l|}{ Gender } \\
\hline Male & 31 & 42 & & \\
\hline Female & 42 & 58 & & \\
\hline \multicolumn{5}{|l|}{ Marital status } \\
\hline Single & 10 & 14 & & \\
\hline In relationship & 20 & 27 & & \\
\hline Married & 40 & 55 & & \\
\hline Separated & 1 & 1 & & \\
\hline Divorced & 2 & 3 & & \\
\hline Years' experience & 73 & 100 & 17.97 & 9.33 \\
\hline \multicolumn{5}{|l|}{ Education } \\
\hline High school & 1 & 1 & & \\
\hline College & 9 & 12 & & \\
\hline University & 63 & 86 & & \\
\hline \multicolumn{5}{|l|}{ Past psychiatric history } \\
\hline No & 31 & 42 & & \\
\hline Yes & 42 & 58 & & \\
\hline Perceived work stress & 73 & 100 & 6.51 & 1.72 \\
\hline $\begin{array}{l}\text { Perceived organisational } \\
\text { support }\end{array}$ & 73 & 100 & 6.33 & 2.26 \\
\hline \multicolumn{5}{|l|}{ Alcohol } \\
\hline Yes & 62 & 85 & & \\
\hline No & 11 & 15 & & \\
\hline Weekly units of alcohol & 62 & 85 & 8.85 & 9.16 \\
\hline Male & 27 & 44 & 10.26 & 7.36 \\
\hline Female & 35 & 56 & 7.77 & 10.30 \\
\hline
\end{tabular}

Job

Job more stressful

\begin{tabular}{|c|c|c|}
\hline Longer hours & 42 & 58 \\
\hline $\begin{array}{l}\text { Covering for unwell } \\
\text { colleagues }\end{array}$ & 4 & 5 \\
\hline $\begin{array}{l}\text { Covering for laid off } \\
\text { colleagues }\end{array}$ & 0 & 0 \\
\hline More demand for stories & 43 & 59 \\
\hline Other & 19 & 26 \\
\hline None & 11 & 15 \\
\hline \multicolumn{3}{|l|}{ Tested for COVID-19 } \\
\hline Yes, positive & 1 & 1 \\
\hline Yes, negative & 5 & 7 \\
\hline $\begin{array}{l}\text { Yes, do not want to } \\
\text { disclose }\end{array}$ & 0 & 0 \\
\hline Yes, TBD & 3 & 4 \\
\hline No & 64 & 88 \\
\hline \multicolumn{3}{|c|}{ Colleagues died from COVID-19 } \\
\hline Yes & 2 & 3 \\
\hline
\end{tabular}

Continued
Table 1 Continued

\begin{tabular}{|c|c|c|c|c|}
\hline & $\mathbf{n}$ & $\%$ & Mean & SD \\
\hline No & 71 & 97 & & \\
\hline \multicolumn{5}{|c|}{ Reported directly on COVID-19 } \\
\hline Yes & 54 & 74 & & \\
\hline No & 19 & 26 & & \\
\hline \multicolumn{5}{|c|}{ Offered therapy/counselling since outbreak } \\
\hline Yes & 38 & 52 & & \\
\hline No & 35 & 48 & & \\
\hline
\end{tabular}

Note: $\mathrm{n}=73$ when not indicated; TBD, to be determined; $A$ unit of alcohol is defined as a regular-size bottle of beer, a glass of wine, or a shot of spirits. Fourteen units of alcohol per week for men and 9 units for women were considered the upper limits of acceptable weekly intake. ${ }^{24}$

experience as a journalist $(\mathrm{r}=0.94, \mathrm{p}<0.001)$ and reporting on COVID-19 directly $(r=-0.30, p<0.001)$. There were no significant differences between journalists who had, or had not, received therapy when it came to age $(M=40.29$, $\mathrm{SD}=9.79$ vs $\mathrm{M}=42.21, \mathrm{SD}=9.78, \mathrm{t}(70)=-0.84, \mathrm{p}=0.404)$. No associations were found between having received therapy since the outbreak and gender $\left(\chi_{(1, N=73)}^{2}=0.167, \mathrm{p}=0.683\right)$, past psychiatric history $\left(\chi_{(1, N=73)}^{2}=0.004, \mathrm{p}=0.948\right)$ or having reported on COVID-19 directly $\left(\chi_{(1, \mathrm{~N}=73)}^{2}=0.003\right.$, $\mathrm{p}=0.953)$.

\section{Psychiatric data}

The psychometric data, including correlations, between the GHQ-12, GAD-7, PHQ-9 and PCL-5 appear in table 2. The percentage of journalists whose scores exceeded thresholds on the GHQ-12, GAD-7, PHQ-9, and PCL-5 was $60(82.2 \%), 19(26 \%), 15(20.5 \%)$, and $7(9.6 \%)$, respectively.

\section{Relationship between demographic and psychiatric data}

Psychiatric differences in, and correlations with, the demographic data are shown in table 3. Most notably, female journalists endorsed more symptoms on the GAD-7 and the PCL-5 than their male counterparts, and journalists with a past psychiatric history reported higher scores on the PHQ-9 and PCL-5. Journalists who reported on COVID-19 directly reported higher scores on the GAD-7. Journalists who had received counselling offered by their news organisation following the onset of the pandemic endorsed fewer symptoms on the GHQ-12, GAD-7, and the PHQ-9 (see figure 1), and reported significantly higher levels of perceived organisational support ( $\mathrm{W}=228$, $\mathrm{p}<0.001)$ and significantly lower levels of perceived work stress $(\mathrm{W}=860, \mathrm{p}<0.05)$. In addition, in terms of threshold scores, they were less likely to score beyond the threshold for caseness on the GHQ-12 (W=623.5, $\mathrm{p}<0.01)$ and the GAD-7 (W=5.5, $\mathrm{p}<0.05)$. Journalists who reported on COVID-19 directly reported higher scores on the GAD-7 and the PHQ-9 than those who did not. 


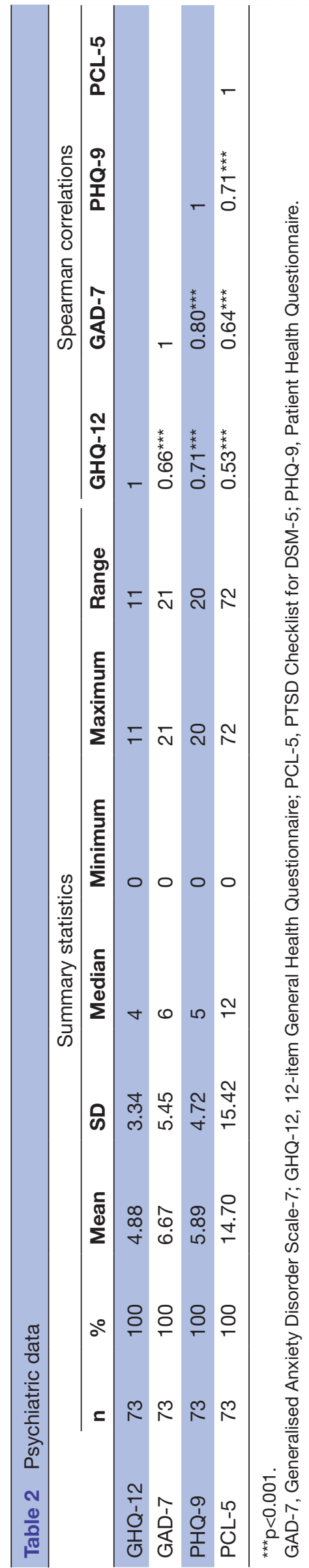

\section{Predictors of psychiatric difficulties}

The number of predictor variables was constrained by sample size. With this in mind, the choice was determined by those independent variables which were found to correlate significantly with symptoms on the psychometric measures, show significant differences within demographic groups, or which historically are known from the psychiatric literature to influence indices of emotional distress. The final predictor variables entered in our generalised linear model were: age, gender, past psychiatric history, therapy provided since the pandemic, and having reported on the pandemic directly. Correlations between these variables were assessed prior to running the analysis to ensure no two variables had a correlation coefficient exceeding $\mathrm{r}=0.6$ (see table 4 ).

The results of the regression analysis appear in table 5 . Age significantly predicted symptoms of PTSD and being female was a significant predictor for elevated scores on all four psychiatric measures. Past psychiatric history was a significant predictor for generalised anxiety disorder, major depression, and PTSD symptoms. Having been offered counselling since the outbreak significantly predicted lower scores on the GHQ-12, the GAD-7, and the PHQ-9. We dichotomised the GAD-7 and PHQ-9 scores into normal and pathologically elevated, and followed this with a post-hoc analysis with Chi-squared (Fisher's exact test), which revealed that journalists who had received mental health therapy were also less likely to fall in the pathological range for the GAD-7 $(p<0.001)$ and PHQ-9 $(\mathrm{p}<0.05)$. Having reported on COVID-19 directly significantly predicted higher GAD-7 and PHQ-9 symptoms.

\section{DISCUSSION}

Results of the regression analysis revealed high rates of psychological distress in journalists working during the COVID-19 pandemic, which were alleviated, in part, by counselling offered by news organisations since the outbreak. Between group comparisons and correlation analyses furthermore revealed that higher rates of general emotional distress, generalised anxiety disorder, and major depression were significantly associated with being female and reporting on the pandemic directly.

Before discussing these results in greater detail, further comment is needed on the sample selection. The participation of two major, international news organisations and the high response rate suggest that the group we studied is broadly reflective of the Western media covering the epidemic. Given that the pandemic dominated the news cycles at the time of data collection, only journalists who reported on current affairs were approached. Studies of email-driven research have shown that acceptance rates of $40 \%$ are considered acceptable, $50 \%$ good, and $60 \%$ and above very good. ${ }^{26}$ With this yardstick in mind, our participation rate of $66 \%$, which overlaps with that obtained in our previous studies with Western journalists, ${ }^{27-29}$ further supports the representative value of our sample. 
Table 3 Psychiatric scores according to demographic factors

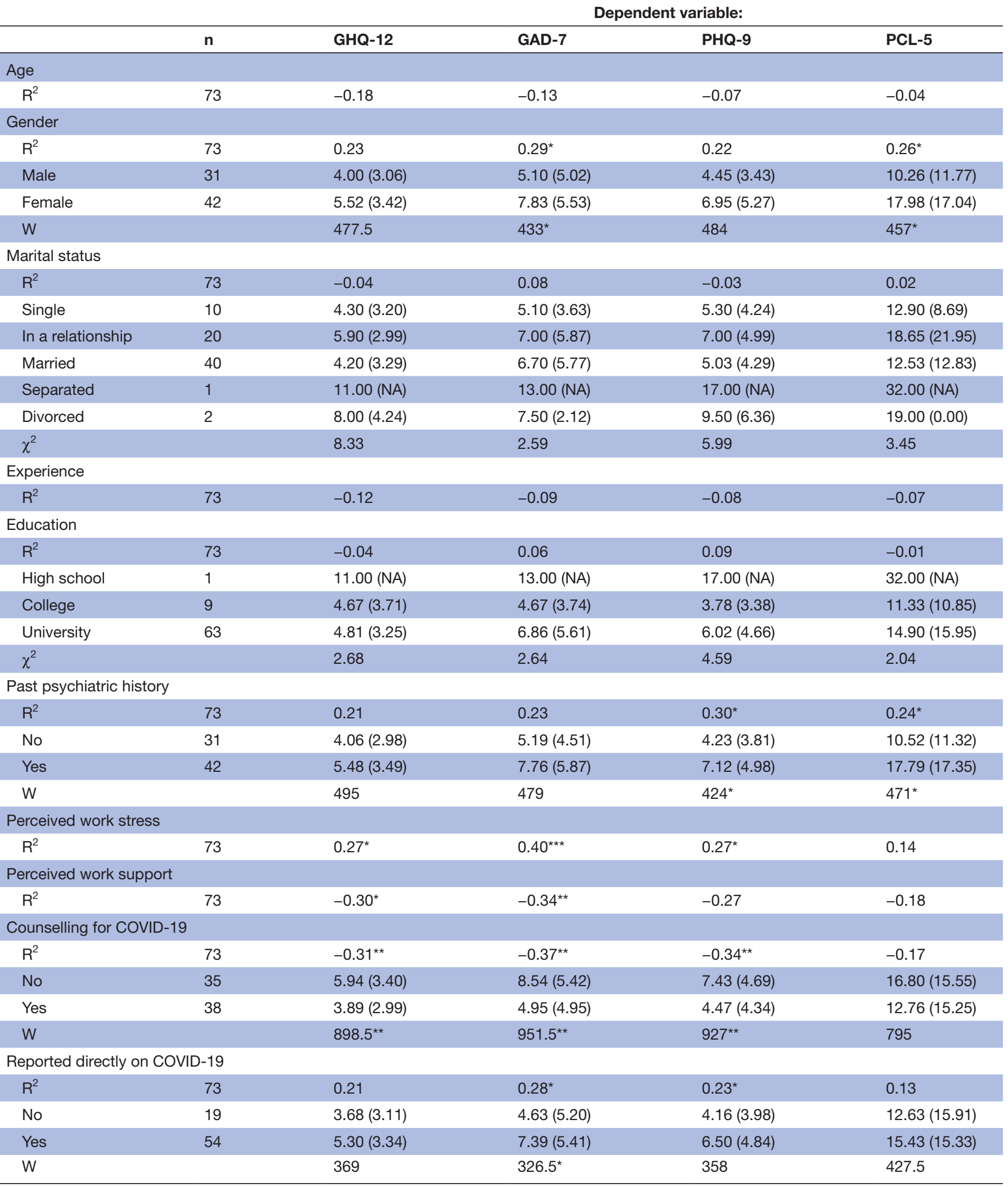

Mean and SD are given for Wilcoxon Rank Sum Tests.

${ }^{\star} p<0.05 ;{ }^{* *} p<0.01 ;{ }^{* \star *} p<0.001$.

GAD-7, Generalised Anxiety Disorder Scale-7; GHQ-12, 12-Item General Health Questionnaire; PCL-5, PTSD Checklist for DSM-5; PHQ-9, Patient Health Questionnaire; $\mathrm{R}^{2}$, correlation coefficient; W, Wilcoxon Rank Sum W. 


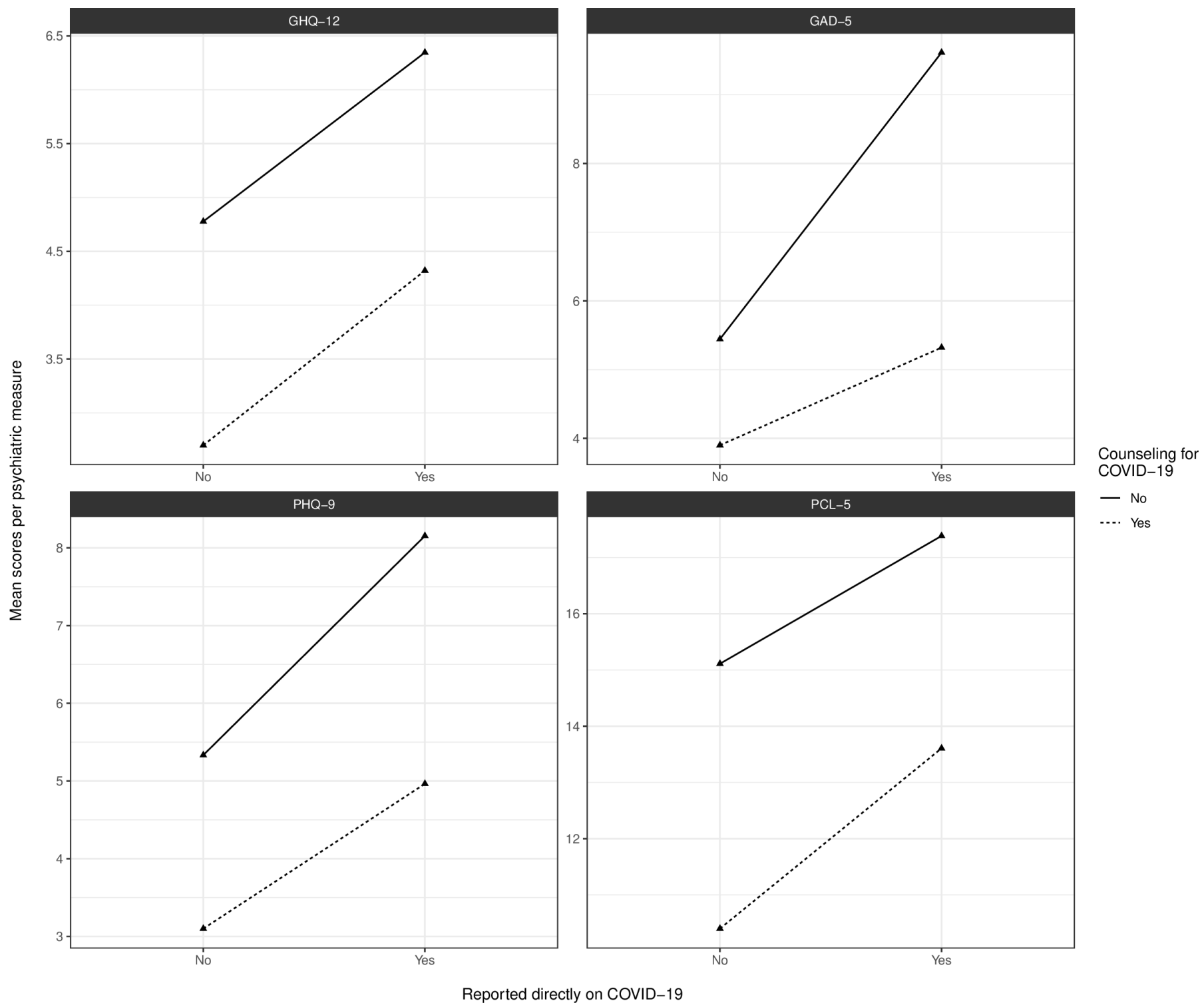

Figure 1 Mean scores per psychiatric measure grouped by directly reported on COVID-19 and counselling for COVID-19.

The COVID-19 pandemic is widely considered the most severe health crisis of the 21st century so far and its impact on all aspects of society cannot be understated. As such, our data must be viewed against the backdrop of elevated levels of psychological distress in the general population. Drawing comparisons between our study and the reported general population findings can, however, be challenging because of demographic mismatch and the potential for cultural bias, as much of the current literature comes from China where rates of anxiety and depression have ranged from $6.3 \%$ to $44.6 \%$ and $17.1 \%$ to $53.5 \%$, respectively. ${ }^{430}$ Data from the UK based on the GHQ-7 and PHQ-9 psychometric scales used in our study, revealed a rate of depression of $22.1 \%$, similar to our sample and a point prevalence of $21.6 \%$ for anxiety, lower than our figure of $26 \% .{ }^{31}$ Not surprisingly, these figures increase in individuals with a history of mental health difficulties pre-pandemic. Anxiety, depression and stressrelated symptoms were significantly higher in those with a premorbid vulnerability compared with those without, following the introduction of lockdown restrictions. ${ }^{32}$ Our data replicated this finding, but with one important caveat; journalists remained out in the field working on COVID-related stories and as such, their lockdown restrictions were social, not occupational.

Given that journalists are considered frontline workers, comparing their mental health to that of other frontline workers is informative. One systematic review and metaanalysis of 12 studies of healthcare workers revealed a $23.2 \%$ prevalence of depression and a $22.8 \%$ prevalence of anxiety, figures that overlap with our sample of journalists. ${ }^{33}$ Another systematic review and meta-analysis, which included a bigger sample of 115 articles, found slightly higher rates of depression and anxiety, namely $26.3 \%$ and $29.0 \%$, respectively. ${ }^{34}$ The findings in our sample approximate these figures. Regarding the results from the PCL-5, it is possible that COVID-19 as a stressor for journalists fell short of the DSM-5 description of what a PTSD stressor 
Table 4 Correlation matrix for demographic predictor variables used in generalised linear regression

\begin{tabular}{|c|c|c|c|c|c|}
\hline & Age & Gender & $\begin{array}{l}\text { Past psychiatric } \\
\text { history }\end{array}$ & $\begin{array}{l}\text { Therapylcounsel for } \\
\text { COVID-19 }\end{array}$ & $\begin{array}{l}\text { Reported directly on } \\
\text { COVID-19 }\end{array}$ \\
\hline Age & 1 & & & & \\
\hline Past psychiatric history & 0.02 & $0.27^{*}$ & 1 & & \\
\hline Therapy/counsel for COVID-19 & 0.09 & -0.05 & 0.01 & 1 & \\
\hline GAD-7 & -0.13 & $0.29^{*}$ & 0.23 & $-0.37^{\star *}$ & $0.28^{*}$ \\
\hline PHQ-9 & -0.07 & 0.22 & 0.30 & $-0.34^{\star \star}$ & $0.23^{*}$ \\
\hline PCL-5 & -0.04 & $0.26^{*}$ & 0.24 & -0.17 & 0.13 \\
\hline
\end{tabular}

Correlations are calculated with Spearman's rank correlation coefficient $\left(R^{2}\right)$.

${ }^{*} \mathrm{p}<0.05 ;{ }^{* \star} \mathrm{p}<0.01$.

GAD-7, Generalised Anxiety Disorder Scale-7; GHQ-12, 12-item General Health Questionnaire; PCL-5, PTSD Checklist for DSM-5; PHQ-9,

Patient Health Questionnaire.

entails, namely exposure to actual or threatened death. ${ }^{23}$ As such the threat to journalists from COVID-19 was perhaps not of a magnitude for it to emerge as a significant predictor for PTSD in our regression analysis. What is notable in our study, however, are the GHQ-12 findings, which should be interpreted as a marker of overall psychological distress. Over $80 \%$ of journalists in our sample were showing evidence of clinically significant emotional distress, a figure more than twice the $37.8 \%$ reported in healthcare workers. ${ }^{34}$ Once again, caution should be adopted when interpreting direct comparisons like this because of methodological constraints, but potential reasons for the high levels of distress found in journalists are likely to be multifactorial.

To begin with, there is the stress of working close to sites of infection like hospitals and medical clinics and

Table 5 Generalised linear models for psychiatric measures

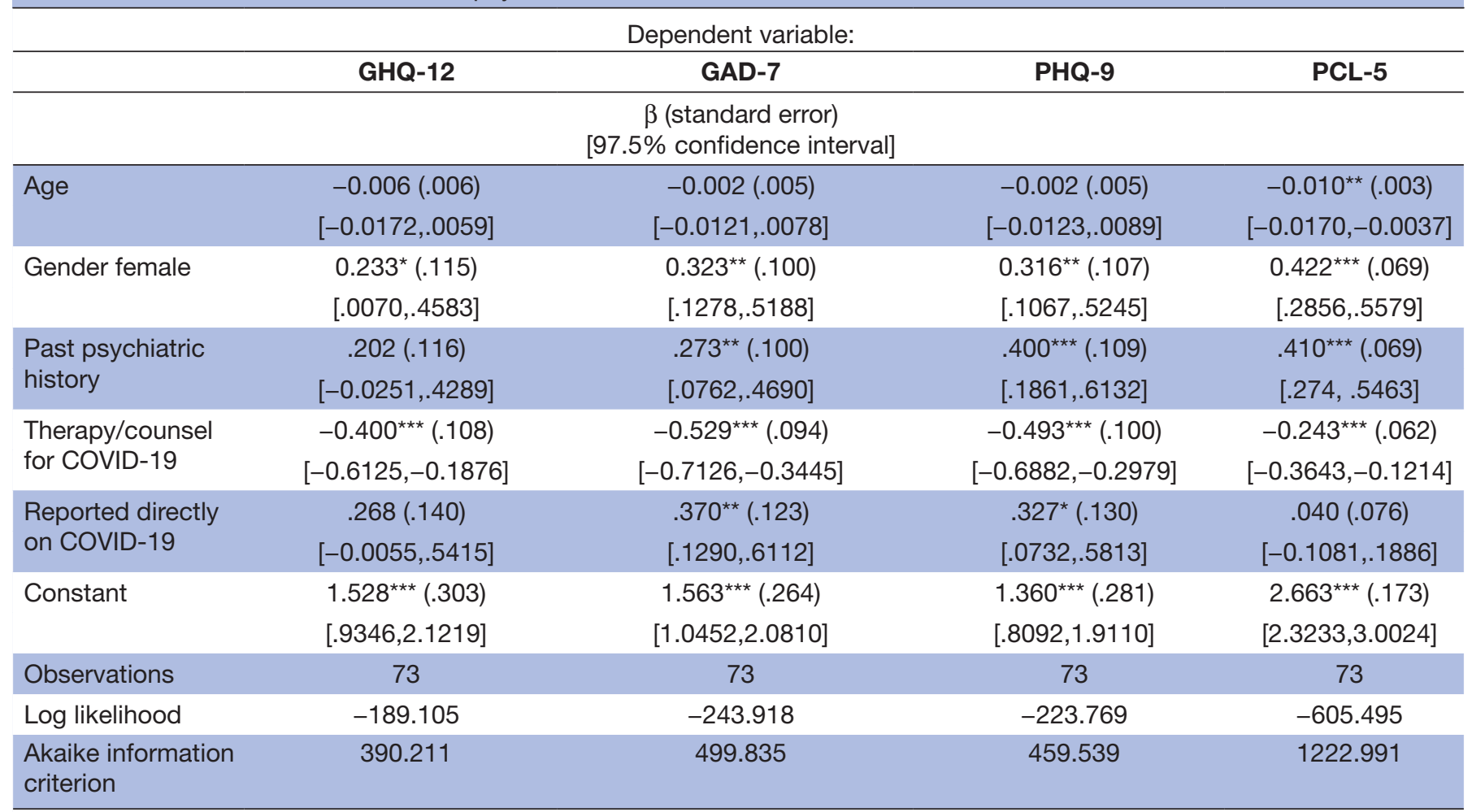

${ }^{*} \mathrm{p}<0.05 ;{ }^{* *} \mathrm{p}<0.01 ;{ }^{* * *} \mathrm{p}<0.001$.

GAD-7, Generalised Anxiety Disorder Scale-7; GHQ-12, 12-item General Health Questionnaire; PCL-5, PTSD Checklist for DSM-5; PHQ-9, Patient Health Questionnaire. 
the emotional challenges of interviewing the bereaved and family members of those taken gravely ill. This point is supported by our data showing that being assigned to cover the pandemic was a statistically significant predictor of elevated scores on the GAD-7 and PHQ-9. This finding adds to a burgeoning literature documenting the psychological effects on journalist who cover risky, dangerous and distressing assignments. ${ }^{35}$ In addition, with most news bureaus closed during lockdowns or working at reduced capacity, journalists have lacked the direct support of colleagues, which can prove protective from a psychological trauma perspective. ${ }^{36}$ Further examples of how COVID-19 has increased work stress for journalists can be found in our demographic data. The majority of journalists felt that their job had become more stressful because of the pandemic, citing longer hours (58\%) and an increased demand for stories (59\%). Of note is that the majority of journalists $(88 \%)$ had not been tested for the virus at the time of data collection. It is now known that uncertainty about a potential infection can exacerbate feelings of fear and unease already present. ${ }^{79}$

An encouraging finding in our study was the emergence of therapy as a protective factor across all four symptom clusters, namely anxiety, depression, PTSD and overall psychological distress. Over $50 \%$ of the sample was offered therapy following the onset of the pandemic, a singular improvement on the part of news who in the past have often looked away from the emotional challenges faced by their journalists working on traumatic assignments. ${ }^{37}$ Furthermore, as can be seen in figure 1 , the benefits of therapy extended not only to those journalists covering the pandemic, but to all those journalists who availed themselves of the offer. As noted above, the stress on journalists was not limited to COVID-related work, but encompassed more generic factors applicable to society at large, such as mandatory social isolation, having to work from home, the loss of leisure pursuits and so on.

In keeping with journalists being offered therapy during the pandemic, another interesting demographic association was found that reflects the sensitivity of news management to the psychological distress of their journalists. The inverse correlation between age and being assigned to work on COVID-19-related news indicates that younger journalists were preferentially selected to work on a potentially hazardous story. Given the often repeated and widely publicised message from public health officials that the outcome of infection with COVID-19 worsened appreciably with age, ${ }^{38}$ our data suggest that news managers to a degree took this knowledge into account when assigning COVID-related stories. The fact that younger journalists were given more risky work also helps explain what at first glance is an anomaly in our psychiatric data, namely the inverse relationship between age and the presence of significant psychopathology, an observation at odds with the trauma literature in journalists. $^{3940}$

Our study is not without limitations. First, data collection relied solely on self-report questionnaires to elicit symptoms. The absence of structured interviews prevented us from obtaining diagnosis of psychiatric disorders according to DSM- 5 criteria. ${ }^{23}$ This is, however, offset to a degree by the robustness of the thresholds on the various psychometric scales as markers of clinical significance. Second, we do not know what kind of counselling journalists received. While the efficacy of in-person and internetbased cognitive behavioural therapy, for example, in treating generalised anxiety disorder, major depression, and PTSD is well established, ${ }^{41-45}$ it may be that simpler supportive measures were also effective in helping journalists through a difficult period. Given that our study design is cross-sectional, we also do not know if any of the benefits will endure. Third, not all journalists who reported on COVID-19 directly did so in person in the field. Instead, a percentage of journalists would have likely worked on the story remotely. Given that both means of coverage were employed, we cannot tease out the relevant contribution of each to the outcome variables. Fourth, we have no data in relation to personal protective equipment access and COVID-19 safety trainings, two variables which in theory could have affected the journalists' emotions. Lastly, we note with interest that journalists assigned to cover the pandemic were younger. The reasons for this are unclear and deserve further exploration.

In summary, our study, the first of its kind, shows that many journalists have struggled emotionally during the pandemic. Journalists fulfil an important function in civil society, keeping a population informed of events that directly impact their day to day functioning. In order for them to continue doing so, they need to remain physically and psychologically healthy. It is therefore encouraging that two major news organisations with a long reach are aware of these challenges and addressing them in a timely fashion. Others that are not doing so need to follow this approach.

Acknowledgements The authors would like to thank Laura Kenton for her assistance.

Contributors $\mathrm{JO}$ was involved in conceptualising the study, analysis of the data and manuscript preparation. MS was involved in conceptualising the study and data collection. AF was involved in conceptualising the study, analysis of the data and manuscript preparation.

Funding The authors have not declared a specific grant for this research from any funding agency in the public, commercial or not-for-profit sectors.

\section{Competing interests None declared.}

Patient consent for publication Not required.

Ethics approval This study received ethics approval from the Research Ethics Board at Sunnybrook Health Sciences Centre fully affiliated with the University of Toronto (approval ID: 065-2015).

Provenance and peer review Not commissioned; externally peer reviewed.

Data availability statement No data are available. We do not have permission to share the data for this study.

Supplemental material This content has been supplied by the author(s). It has not been vetted by BMJ Publishing Group Limited (BMJ) and may not have been peer-reviewed. Any opinions or recommendations discussed are solely those of the author(s) and are not endorsed by BMJ. BMJ disclaims all liability and responsibility arising from any reliance placed on the content. Where the content includes any translated material, BMJ does not warrant the accuracy and reliability 
of the translations (including but not limited to local regulations, clinical guidelines, terminology, drug names and drug dosages), and is not responsible for any error and/or omissions arising from translation and adaptation or otherwise.

Open access This is an open access article distributed in accordance with the Creative Commons Attribution Non Commercial (CC BY-NC 4.0) license, which permits others to distribute, remix, adapt, build upon this work non-commercially, and license their derivative works on different terms, provided the original work is properly cited, appropriate credit is given, any changes made indicated, and the use is non-commercial. See: http://creativecommons.org/licenses/by-nc/4.0/.

\section{ORCID iD}

Jonas 0smann http://orcid.org/0000-0002-2540-4824

\section{REFERENCES}

1 Pan $\mathrm{Y}$, Guan H, Zhou S, et al. Initial CT findings and temporal changes in patients with the novel coronavirus pneumonia (2019-nCoV): a study of 63 patients in Wuhan, China. Eur Radiol 2020;30:3306-9.

2 Dong E, Du H, Gardner L. An interactive web-based dashboard to track COVID-19 in real time. Lancet Infect Dis 2020;20:533-4.

3 Qiu J, Shen B, Zhao M, et al. A nationwide survey of psychological distress among Chinese people in the COVID-19 epidemic: implications and policy recommendations. Gen Psychiatr 2020;33:e100213.

4 Wang C, Pan R, Wan X, et al. Immediate psychological responses and associated factors during the initial stage of the 2019 coronavirus disease (COVID-19) epidemic among the general population in China. Int J Environ Res Public Health 2020;17:1729.

5 Salari N, Hosseinian-Far A, Jalali R, et al. Prevalence of stress, anxiety, depression among the general population during the COVID-19 pandemic: a systematic review and meta-analysis. Global Health 2020;16:1-11.

6 Tan W, Hao F, Mclntyre RS, et al. Is returning to work during the COVID-19 pandemic stressful? A study on immediate mental health status and psychoneuroimmunity prevention measures of Chinese workforce. Brain Behav Immun 2020;87:84-92.

7 Mertens G, Gerritsen L, Duijndam S, et al. Fear of the coronavirus (COVID-19): predictors in an online study conducted in March 2020. $J$ Anxiety Disord 2020;74:102258.

8 Ahorsu DK, Lin C-Y, Imani V, et al. The Fear of COVID-19 Scale: Development and Initial Validation. Int J Ment Health Addict 2020;1.

9 Lee SA. Coronavirus anxiety scale: a brief mental health screener for COVID-19 related anxiety. Death Stud 2020;44:393-401.

10 Cao W, Fang Z, Hou G, et al. The psychological impact of the COVID-19 epidemic on college students in China. Psychiatry Res 2020;287:112934.

11 Mo Y, Deng L, Zhang L, et al. Work stress among Chinese nurses to support Wuhan in fighting against COVID-19 epidemic. J Nurs Manag 2020;28:1002-9.

12 Stogner J, Miller BL, McLean K. Police stress, mental health, and Resiliency during the COVID-19 pandemic. American Journal of Criminal Justice 2020;45:718-30.

13 Vagni M, Maiorano T, Giostra V, et al. Hardiness, stress and secondary trauma in Italian healthcare and emergency workers during the COVID-19 pandemic. Sustainability 2020;12:5592.

14 Spoorthy MS, Pratapa SK, Mahant S. Mental health problems faced by healthcare workers due to the COVID-19 pandemic-A review. Asian J Psychiatr 2020;51:102119.

15 Osofsky HJ, Holloway H, Pickett A. War correspondents as responders: considerations for training and clinical services. Psychiatry 2005;68:283-93.

16 Feinstein A, Audet B, Waknine E. Witnessing images of extreme violence: a psychological study of journalists in the newsroom. JRSM Open 2014;5:205427041453332.

17 Feinstein A, Pavisian B, Storm $\mathrm{H}$. Journalists covering the refugee and migration crisis are affected by moral injury not PTSD. JRSM Open 2018;9:205427041875901-7.

18 Qualtrics. Qualtrics, 2020. Available: https://www.qualtrics.com

19 Goldberg D, Williams P. A user's guide to the ghq. Windsor: NFERNelson, 1988.

20 Spitzer RL, Kroenke K, Williams JBW, et al. A brief measure for assessing generalized anxiety disorder: the GAD-7. Arch Intern Med 2006;166:1092-7.
21 Kroenke K, Spitzer RL. The phq-9: a new depression diagnostic and severity measure. Psychiatr Ann 2002;32:509-15.

22 Weathers FW, Litz BT, Keane TM, et al. The PTSD checklist for DSM5 (PCL-5); 10, 2013. Available: https://www.ptsd.va.gov

23 American Psychiatric Association. Diagnostic and statistical manual of mental disorders. 5th ed. Washington, DC: Author, 2013.

24 Bondy SJ, Rehm J, Ashley MJ, et al. Low-Risk drinking guidelines: the scientific evidence. Can J Public Health 1999;90:264-70.

25 R Core Team. R: a language and environment for statistical computing. Vienna, Austria: R Foundation for Statistical Computing, 2019. https://www.R-project.org/

26 Hamilton MB. Online survey response rates and times: background and guidance for industry. Longmont: Ipathia, 2009.

27 Feinstein A, Wanga J, Owen J. The psychological effects of reporting extreme violence: a study of Kenyan journalists. JRSM Open 2015;6:205427041560282-6.

28 Feinstein A, Starr S. Civil war in Syria: the psychological effects on journalists. J Aggress Confl Peace Res 2015;7:57-64.

29 Osmann J, Khalvatgar AM, Feinstein A. Psychological distress in Afghan journalists: a descriptive study. J Aggress Confl Peace Res 2020;12:115-23.

30 Liu D, Ren Y, Yan F, et al. Psychological impact and predisposing factors of the coronavirus disease 2019 (COVID-19) pandemic on general public in China. SSRN Journal 2020.

31 Shevlin M, Nolan E, Owczarek M, et al. COVID-19-related anxiety predicts somatic symptoms in the UK population. $\mathrm{Br} \mathrm{J}$ Health Psychol 2020;25:875-82.

32 Hao F, Tan W, Jiang L, et al. Do psychiatric patients experience more psychiatric symptoms during COVID-19 pandemic and lockdown? A case-control study with service and research implications for immunopsychiatry. Brain Behav Immun 2020;87:100-6.

33 Pappa S, Ntella V, Giannakas T, et al. Prevalence of depression, anxiety, and insomnia among healthcare workers during the COVID-19 pandemic: a systematic review and meta-analysis. Brain Behav Immun 2020;88:901-7.

34 Salazar de Pablo G, Vaquerizo-Serrano J, Catalan A, et al. Impact of coronavirus syndromes on physical and mental health of health care workers: systematic review and meta-analysis. J Affect Disord 2020;275:48-57.

35 Osmann J, Dvorkin J, Inbar Y, et al. The emotional well-being of journalists exposed to traumatic events: a mapping review. Media, War \& Conflict 2020;1:175063521989599.

36 Greden JF, Valenstein M, Spinner J, et al. Buddy-to-Buddy, a citizen soldier peer support program to counteract stigma, PTSD, depression, and suicide. Ann N Y Acad Sci 2010;1208: 90-7.

37 Feinstein A. Journalists under fire: the psychological hazards of covering war. Baltimore: JHU Press, 2006.

38 Centers for Disease Control and Prevention. Older adults, 2020. Available: https://www.cdc.gov/coronavirus/2019-ncov/need-extraprecautions/older-adults.html

39 Lee M, Ha EH, Pae JK. The exposure to traumatic events and symptoms of posttraumatic stress disorder among Korean journalists. Journalism 2018;19:1308-25.

40 McMahon C. Covering disaster: a pilot study into secondary trauma for print media journalists reporting on disaster. The Australian Journal of Emergency Management 2001;16:52.

41 Ehlers A. Trauma-focused cognitive behavior therapy for posttraumatic stress disorder and acute stress disorder. New York, NY: Wiley, 2013.

42 Cuijpers P, Sijbrandij M, Koole SL, et al. The efficacy of psychotherapy and pharmacotherapy in treating depressive and anxiety disorders: a meta-analysis of direct comparisons. World Psychiatry 2013;12:137-48.

43 Acarturk C, Cuijpers P, van SA. Psychological treatment of social anxiety disorder: a meta-analysis. In: database of abstracts of reviews of effects (Dare): Quality-assessed reviews. York (UK: Centre for Reviews and Dissemination (UK), 2009.

44 Ho CS, Chee CY, Ho RC, CS H, Ho RC others. Mental health strategies to combat the psychological impact of COVID-19 beyond paranoia and panic. Ann Acad Med Singap 2020;49:1-3.

45 Zhang MWB, Ho RCM, Ho R. Moodle: the cost effective solution for internet cognitive behavioral therapy (I-CBT) interventions. Technol Health Care 2017;25:163-5. 